www.jmscr.igmpublication.org

Index Copernicus Value: 79.54

ISSN (e)-2347-176x ISSN (p) 2455-0450

crossrefDOI: https://dx.doi.org/10.18535/jmscr/v7i2.106

\title{
Altered Mental Status: Diagnostic value of various clinical parameters and diagnostic accuracy in emergency department
}

\author{
Authors \\ Hilal A Sheikh, Wani A. Mushtaq \\ Sheri-Kashmir Institute of Medical Science \\ Email:drhilal@gmail.com
}

\begin{abstract}
Background: Evaluation of a patient with Altered Mental Status AMS in the Emergency department ED is difficult for many reasons. Emergency physician is usually expected to make q a correct working provisional diagnosis in AMS in quick time; and the accuracy of this provisional diagnosis has an important bearing sometimes on prognosis of patient Objective: The Aim of the study was to determine retrospectively the diagnostic accuracy in the Emergency Department and to determine diagnostic value of various components of clinical evaluation.

Methods: The study was conducted prospectively in 201 patients who presented to a tertiary care hospital with AMS .Children, and patients with history of dementia, psychiatric disease, were excluded. History and examination was done, and provisional diagnosis made. CT scan head \& CSF analysis were routinely done. All required investigations were done to reach the final diagnosis.

Results: In $11.4 \%$ provisional diagnosis did not match with final diagnosis, in $16.4 \%$, diagnosis matched partially, in $71.6 \%$ diagnosis matched completely. The specific features of the clinical evaluation of diagnostic value followed by rates of positive diagnostic finding included: History 76.6\%, Examination 65.7\%, CBC 4\%, and Blood sugar $11.4 \%$. KFT6\%, ABG 9.5\%, Electrolytes5\%, LFT3.5\%, CSF6\%,CT Scan 37.3\%, CXR 8.5\%, ECG3.5\%,others 8.5\%.

Conclusion: There was very good match between initial provisional diagnosis and final diagnosis at discharge. The features of clinical evaluation having highest positive diagnostic value were history, examination, CT head and blood sugar.

Keywords: Altered Mental Status; Diagnostic accuracy; evaluation of AMS ; clinical parameters; Diagnostic value.
\end{abstract}

\section{Introduction}

Altered mental status (AMS) is a collective phrase describing the undifferentiated presentation of disorders of mentation, including impaired cognition, diminished attention, reduced awareness, and/or altered level of consciousness ${ }^{1}$. Patients with acute non-traumatic causes of AMS make up 5\% of all patients presenting to emergency departments (ED). ${ }^{1}$ with higher rates (20-25\%) among elderly. ${ }^{2,3}$
Evaluation of a patient with AMS in the ED is difficult for many reasons. In most instances, the altered mentation prevents a thorough and complete history; unless the patient is accompanied by an informed attendant, crucial details from the presentation may be lacking. Sometimes, the baseline mental functioning is unknown; and an individual with baseline chronic impairment of function who presents with superimposed AMS may provide an especially problematic challenge to evaluation. In the 
majority of encounters, an alteration in mentation is apparent, but the etiology is not immediately obvious. AMS may also take many forms, ranging from complete unresponsiveness to extreme hyperactivity. Emergency physician is usually expected to make quickly a correct working provisional diagnosis; and the accuracy of this provisional diagnosis has an important bearing sometimes on prognosis of patient. And he has to choose relevant and specific investigations to reach to a correct diagnosis. Thus specific diagnosis and treatment of AMS is highly challenging for emergency physicians.

\section{Material and Methods}

The Aim of the study was to determine retrospectively the diagnostic accuracy in the ED and to determine diagnostic value of various components of clinical evaluation.

The study after getting cleared by ethics committee was conducted prospectively on random days in consecutive patients who came to Emergency Department ED of a tertiary care hospital in north India. Participants were patients with AMS prospectively diagnosed by Emergency Physician EP.

Inclusion criteria: Emergency physician identified any one of the following criteria for the patient at the time of initial presentation:

- Glasgow Coma Scale score less than 15.

- Patient not alert and not oriented to person, place, and/or time;

- Difficult to arouse; unable to remain awake or conversant;

- Hallucinations; confusion; bizarre or inappropriate behavior;

Exclusion criteria: Age less than 14, Any obvious evidence of trauma, Psychiatric Disease, A known patient of dementia

A proper history was take from patient, attendants, and other sources if above was not available. Thorough examination was done. A provisional working diagnosis was made and documented by emergency physician. Baseline investigations (complete blood count $\mathrm{CBC}$, kidney function test
KFT, Blood Sugar, Blood gas and electrolytes, Chest X-ray, ECG) were done. CT HEAD \& CSF were also done routinely, unless there was a contraindication for CSF and time permitted these investigations.

All the required tests as per the requirement of patient's condition were done which included a chemistry panel, ABG \& electrolytes. All other investigations needed to be done to establish a correct diagnosis (including culture of body fluids, EEG, MRI brain, serum cortisol etc) were done. Patients were followed during the hospital stay (when shifted to other specialties) till their discharge or death. Final diagnosis was established after a consensus. Autopsy was not done.

\section{Results}

After taking history and examination, a diagnosis was given, which was later on compared with the final diagnosis. In $11.4 \%$ diagnosis did not match, in $16.4 \%$, diagnosis matched partially, in $71.6 \%$ diagnosis matched completely as shown in table 1. It was said to have completely matched if the diagnosis at discharge was same as that of provisional diagnosis. But we did not scrutinize the provisional diagnosis for details e.g. if the emergency physician had made a diagnosis of stroke - likely hemorrhagic and final diagnosis was a putaminal hemorrhage we took it as correct diagnosis as the next logical step would have been $\mathrm{Ct}$ head which would have been mandatory in any case to confirm the diagnosis in a suspected stroke.

It was either said to have partially matched; if for instance a patient was given a diagnosis of AMS due to metabolic cause and then patient turned out to be having hyponatremia, diagnosis was said to have partially matched; because invariably line of management would not have changed and next step would be to order chemistry panel to look for which metabolic derangement existed. Likewise if initial diagnosis was stroke matched category and final diagnosis was Sub Dural hematoma; again it was put in partially matched category as again line 


\section{JMSCR Vol||07||Issue||02||Page 596-602||February}

of management would not change as next step would have been it turned .finally if the diagnosis did not match it was put under not matched category .

Further the comparison and correlation of initial provisional diagnosis and final diagnosis in each etiological category of AMS like stroke, metabolic derangement, infection, poisoning etc is shown in table 2. In the history of past illness; history of similar type of AMS in past was present in 30 patients out of 201 (15\% of patients). It was present in 12 patients of metabolic causes of AMS, 6 patients of seizure, 5 patients of stroke, 2 patients of cardiovascular cause of AMS, 2 patients of SDH, 2 patients of infection and 1 patients of intra-cranial infection.

Most of the patients (65\%) had normal general physical examination (GPE). The most common abnormality on GPE was pallor, followed in descending order by cyanosis, icterus, and fever peripheral edema as shown in table 3.
The specific features of the clinical evaluation of diagnostic value followed by rates of positive diagnostic finding are shown in table 4 . The CT diagnosis in the patients is shown in the table 5 . Sixty six had normal CT head. Though we had planned to do CT head in all patients; in 28 patients CT could not be done, either other diagnostic modalities took priority or a therapeutic procedure precluded it from being done and in other patients it could not be got after they had for example dramatic recovery .e.g. Hypoglycemia, poisoning.

Table 1: Showing the diagnostic accuracy of history and examination

\begin{tabular}{lcc}
\hline $\begin{array}{l}\text { Diagnosis } \\
\text { Match }\end{array}$ & $\begin{array}{c}\text { Number-of } \\
\text { patients }\end{array}$ & Percent \\
\hline Partially & 34 & 16.9 \\
Completely & 144 & 71.6 \\
No & 23 & 11.4 \\
\hline Total & 201 & 100.0 \\
\hline
\end{tabular}

Table 2: Showing correlation between final diagnoses and Initial diagnoses (diagnoses made on initial clinical assessment)

\begin{tabular}{|c|c|c|c|c|c|c|c|c|c|c|c|c|}
\hline & \multicolumn{5}{|c|}{ I N IT IA L } & \multicolumn{6}{|c|}{ D IA GNOS IS } & \multirow[b]{2}{*}{ Total } \\
\hline & & CVA & Metabolic & Infection & $\begin{array}{c}\text { I-C } \\
\text { †Ifection }\end{array}$ & Seizure & Poisoning & ICSOL & $\begin{array}{l}\text { Cardio- } \\
\text { vascular }\end{array}$ & SDH & Misc & \\
\hline \multirow{10}{*}{$\begin{array}{l}\mathrm{D} \\
\mathrm{I} \\
\mathrm{A} \\
\mathrm{G} \\
\mathrm{N} \\
\mathrm{O} \\
\mathrm{S} \\
\mathrm{I} \\
\mathrm{S}\end{array}$} & CVA & $\begin{array}{c}53 \\
(91.4 \%) \\
\end{array}$ & & & $\begin{array}{c}1 \\
(1.7 \%)\end{array}$ & $\begin{array}{c}3 \\
(5.2 \%) \\
\end{array}$ & & & & $\begin{array}{c}1 \\
(1.7 \%) \\
\end{array}$ & & $\begin{array}{c}58 \\
(100.0 \%)\end{array}$ \\
\hline & Metabolic & $\begin{array}{c}5 \\
(9.8 \%) \\
\end{array}$ & $\begin{array}{c}37 \\
(72.5 \%) \\
\end{array}$ & $\begin{array}{c}4 \\
(7.8 \%)\end{array}$ & & $\begin{array}{c}3 \\
(5.9 \%)\end{array}$ & $\begin{array}{c}1 \\
(2.0 \%)\end{array}$ & & $\begin{array}{c}1 \\
(2.0 \%)\end{array}$ & & & $\begin{array}{c}51 \\
(100.0 \%)\end{array}$ \\
\hline & Infection & & $\begin{array}{c}4 \\
(23.5 \%) \\
\end{array}$ & $\begin{array}{c}13 \\
(76.5 \%) \\
\end{array}$ & & & & & & & & $\begin{array}{c}17 \\
(100.0 \%) \\
\end{array}$ \\
\hline & I-C Infection & $\begin{array}{c}1 \\
(6.7 \%) \\
\end{array}$ & $\begin{array}{c}1 \\
(6.7 \%) \\
\end{array}$ & $\begin{array}{c}2 \\
(13.3 \%) \\
\end{array}$ & $\begin{array}{c}9 \\
(60.0 \%) \\
\end{array}$ & & & & & $\begin{array}{c}2 \\
(13.3 \%) \\
\end{array}$ & & $\begin{array}{c}15 \\
(100.0 \%)\end{array}$ \\
\hline & Seizure & & & $\begin{array}{c}1 \\
(7.7 \%)\end{array}$ & & $\begin{array}{c}12 \\
(92.3 \%)\end{array}$ & & & & & & $\begin{array}{c}13 \\
(100.0 \%)\end{array}$ \\
\hline & Poisoning & & & & & & $\begin{array}{c}11 \\
(100.0 \%) \\
\end{array}$ & & & & & $\begin{array}{c}11 \\
(100.0 \%) \\
\end{array}$ \\
\hline & ICSOL & $\begin{array}{c}2 \\
(20.0 \%)\end{array}$ & $\begin{array}{c}1 \\
(10.0 \%)\end{array}$ & $\begin{array}{c}1 \\
(10.0 \%)\end{array}$ & $\begin{array}{c}3 \\
(30.0 \%)\end{array}$ & & & $\begin{array}{c}3 \\
(30.0 \%)\end{array}$ & & & & $\begin{array}{c}10 \\
(100.0 \%) \\
\end{array}$ \\
\hline & Cariovascular & $\begin{array}{c}1 \\
(9.1 \%)\end{array}$ & $\begin{array}{c}1 \\
(9.1 \%)\end{array}$ & & $\begin{array}{c}1 \\
(9.1 \%)\end{array}$ & & & & $\begin{array}{c}6 \\
(54.5 \%)\end{array}$ & & $\begin{array}{c}2 \\
(18.2 \%)\end{array}$ & $\begin{array}{c}11 \\
(100.0 \%)\end{array}$ \\
\hline & SDH & $\begin{array}{c}4 \\
(57.1 \%)\end{array}$ & & $\begin{array}{c}1 \\
(14.3 \%)\end{array}$ & & & & $\begin{array}{c}2 \\
(28.6 \%)\end{array}$ & & & & $\begin{array}{c}7 \\
(100.0 \%)\end{array}$ \\
\hline & Misc & $\begin{array}{c}1 \\
(12.5 \%)\end{array}$ & $\begin{array}{c}2 \\
(25.0 \%)\end{array}$ & $\begin{array}{c}1 \\
(12.5 \%)\end{array}$ & $\begin{array}{c}1 \\
(12.5 \%)\end{array}$ & & & & & & $\begin{array}{c}3 \\
(37.5 \%)\end{array}$ & $\begin{array}{c}8 \\
(100.0 \%)\end{array}$ \\
\hline & Total & $\begin{array}{c}67 \\
(33.3 \% \\
\end{array}$ & $\begin{array}{c}46 \\
(22.9 \%)\end{array}$ & $\begin{array}{c}23 \\
(11.4 \%)\end{array}$ & $\begin{array}{c}15 \\
(7.5 \%)\end{array}$ & $\begin{array}{c}18 \\
(9.0 \%)\end{array}$ & $\begin{array}{c}12 \\
(6.0 \%)\end{array}$ & $\begin{array}{c}5 \\
(2.5 \%)\end{array}$ & $\begin{array}{c}7 \\
(3.5 \%)\end{array}$ & $\begin{array}{c}3 \\
(1.5 \%)\end{array}$ & $\begin{array}{c}5 \\
(2.5 \%)\end{array}$ & $\begin{array}{c}201 \\
(100.0 \%)\end{array}$ \\
\hline
\end{tabular}

[Note: I.C infection denotes intracranial infection and Misc denotes Miscellaneous] 
Table 3: Showing the frequency of various features of general physical examination

\begin{tabular}{l|cc}
\hline General Physical Examination & Number-of patients & Percent \\
\hline Normal & 130 & $65 \%$ \\
Abnormal breathing & 7 & $3.5 \%$ \\
Cyanosis & 17 & $8.5 \%$ \\
Fasciculations & 2 & $1 \%$ \\
Fever & 9 & $4.5 \%$ \\
Asterexis & 6 & $3 \%$ \\
Icterus & 10 & $5 \%$ \\
Raised JVP & 6 & $6 \%$ \\
Myoclonus & 2 & $1 \%$ \\
Oral candidiasis & 1 & $0.5 \%$ \\
Pallor & 27 & $23.5 \%$ \\
Edema & 8 & $4 \%$ \\
Rash & 4 & $2 \%$ \\
Weak carotids & 3 & $1.5 \%$ \\
Signs-of hypocalcaemia & 1 & $0.5 \%$ \\
\hline
\end{tabular}

Table 4: Showing positive diagnostic values of various features of clinical evaluation

\begin{tabular}{l|cc}
\hline Diagnostic Evaluation & Positive & Percentage \\
\hline History & 154 & $76.6 \%$ \\
Examination & 132 & $65.7 \%$ \\
CBC & 8 & $4 \%$ \\
B SUGAR & 32 & $11.4 \%$ \\
KFT & 12 & $6 \%$ \\
ABG & 19 & $9.5 \%$ \\
Electrolytes & 10 & $5 \%$ \\
LFT & 7 & $3.5 \%$ \\
CSF & 12 & $6 \%$ \\
CT Scan Head & 75 & $37.3 \%$ \\
Chest Xray & 17 & $8.5 \%$ \\
ECG & 7 & $3.5 \%$ \\
Others & 17 & $8.5 \%$ \\
\hline
\end{tabular}

Table 5: Showing various findings on CT Head

\begin{tabular}{l|cc}
\hline CT Diagnosis & Number-of patients & Percent \\
\hline Atrophy & 9 & 4.5 \\
Brain abscess & 1 & .5 \\
Basal-ganglion calcification & 1 & .5 \\
Edema & 6 & 3.0 \\
Gliosis & 10 & 5.0 \\
Hydrocephalus & 2 & 1.0 \\
Hemorrhage & 31 & 15.4 \\
ICSOL & 6 & 3.0 \\
Infarct & 21 & 10.4 \\
Lacunae & 2 & 1.0 \\
Metastasis & 2 & 1.0 \\
MREL* & 2 & 1.0 \\
Not done & 28 & 13.9 \\
Normal & 66 & 32.8 \\
Scalp edema & 2 & 1.0 \\
SDH & 12 & 6.0 \\
\hline Total & 201 & 100.0 \\
\hline
\end{tabular}

*Multiple ring enhancing lesions.

\section{Discussion}

We found the provisional diagnosis made by emergency physician after history and examination matched in good number of patients. In $71.6 \%$ diagnosis matched completely and on grouping the completely and partially matched 
groups we found that $88.6 \%$ patients received the correct working diagnosis after initial assessment (history and examination). Thus we find that history and examination are important and most useful tools for correct provisional diagnosis in emergency department. Whereas more dramatic diagnosis were not missed and were given correct initial diagnosis as is shown by high percentage of accurate diagnosis in CVA 56 patients (96.9\%), seizure $13(100 \%)$ poisoning 11(100 \%), SDH $11(100 \%)$. Diagnostic accuracy was less in metabolic group; 14 patients (72.6\%) were diagnosed correctly initially, similarly ICSOL group only 5 patients $(55.55 \%)$ were diagnose correctly and in intracranial infection group only $6(60 \%)$ were diagnosed correctly and this was statistically significant if we compared the proportions of correct diagnoses with CVA group most common group in our study. On the converse If we considered the initial diagnosis (based on history and examination) as bench mark; AMS because of infection was over diagnosed 23 patients were given label of infection as against 17 as proven in the final diagnosis. This underscores need for ordering CT Scan Head and CSF examination in neurological causes of AMS and simple tests like blood count, blood sugar, chemistry panel, lactate level, Chest X-ray, urine examination in emergency department especially in patients of non-neurological cause of AMS to aid in correct diagnosis of such patients.

In a study the emergency physician's initial diagnosis (formed within the first $20 \mathrm{~min}$ of patient assessment) for patients with AMS showed good accuracy and that the physician's initial degree of confidence correlated with higher accuracy. ${ }^{4}$ Conversely in a study from a singlecenter showed that misdiagnosis of AMS patients was as high as $75 \%$ in delirium patients of more than 65 years old. ${ }^{5}$

In our study CT scan of head showed some form of abnormality in 113 patients as shown in table 5 . Though the positive diagnostic value was only in 75 patients. Hemorrhage was seen Ct scans of 31 patients and was number one abnormality .This is in contrast to the fact that globally ischemic stroke is number one cause of stroke ${ }^{6}$; but in our population hemorrhagic stroke has been shown to be more common ${ }^{7}$. And further hemorrhagic strokes are more likely to present in AMS than ischemic strokes. ${ }^{8}$ CT head is valuable to pick up structural causes of coma which might be missed as reflected by misdiagnosis of etiology of AMS in patients who turned out to be having ICSOL. We found that many patients with AMS exhibited negative CT results. In a study done in AMS patients, the CT diagnosis rate for AMS etiology was only $15 \% .^{9}$ And sometimes over reliance on CT scan can lead to negative impact on the diagnosis of non-neurological causes of AMS. Even though the value of a negative CT-head is important in a given clinical setting, and further it can elucidate a concomitant brain insult in an appropriate clinical setting eg., in acute poisoning CT scan can help to elucidate whether or not combined with brain injury. ${ }^{10}$

Moreover the diagnostic value depends upon the composition of the cohort of patients. In a study of the 106 patients with an initial diagnosis, 52 (51\%) had a head CT performed, with only eight (8\%) having an acute abnormality ${ }^{4}$. But on looking at the final consensus diagnosis in this study 66 out of 106 had some form of intoxication, 22 had psychotic episodes or dementia, 6 had metabolic derangement, and one had septic encephalopathy. They had only four strokes/TIAs, 4 seizures and 3 traumatic brain injuries thus explaining the low CT positivity.

To rationalize the use of CT scan of head various guiding principles have been suggested in studies. But, studies on patients with AMS using brain CT are limited. Several guidelines for brain CT have been developed, but are mostly relevant to traumatic brain injuries. ${ }^{11,12,}$ Hardy and Brennan ${ }^{13}$ evaluated the brain CT of elderly patients (aged $>70$ years) with acute confusion, noting that positive findings were detected in only $14 \%$. Leong et al ${ }^{10}$ evaluated 382 Head CT scans performed on patients with AMS at an Emergency department. They reported that diastolic blood 
pressure of $>80 \mathrm{mmHg}$, GCS score of $<15$, focal weakness, extensor plantar response, dilated pupils, and use of antiplatelet and anticoagulant medications were factors associated with abnormal CT findings. While as in other study looking for predictors of abnormal brain computed tomography findings in patients with acute altered mental status in the emergency department showed, initial GCS scores of $<9$ and CRP levels of $<2 \mathrm{mg} / \mathrm{dl}$ also correlated with positive brain CT findings. ${ }^{14}$

On looking for various components of the clinical evaluation with rates of positive diagnostic value; we found History $76.6 \%$ and examination $65.7 \%$ with most helpful. History of similar type of AMS in past was present in $15 \%$ of patients. It was increasingly present in metabolic, seizure and SDH patients in percentages of $23 \%, 46 \%$ and $28 \%$ respectively and obviously helped in these patients to formulate a provisional diagnosis. In a similar study by xiao $\mathrm{H} \mathrm{Y}$ et al the previous history of AMS was seen in $32 \% .^{9}$ This simple enquiry may help the emergency physician in getting a clue to cause of AMS in emergency department. General physical examination is usually helpful in metabolic, infective, poisoning causes of encephalopathy as is shown in table 3; with most common findings being pallor, cyanosis, jaundice, fever, icterus and peripheral edema. Sometimes they can be clinching e.g. fasciculations in two patients suggested organophosphorus compound as cause of poisoning .Similarly asterexis usually would point to a metabolic cause of AMS We could not find any study showing features on general physical examination in AMS patients for comparison.

Among investigations CT Head $37.3 \%$ and Blood sugar 11.4 were helpful. The high positive diagnostic value was because our cohort consisted of high number of stroke. Random Blood sugar had higher positive diagnostic value than Chest Xray, ECG, Chemistry panel, ABG, the 12-lead electrocardiogram, and laboratory studies. Thus random blood sugar was of highest positive diagnostic value among nonstructural causes of
AMS and should be done first investigation done routinely in all AMS patients .CSF examination had positive diagnostic value in was $6 \%$. A study showed that the cerebrospinal fluid analysis of acute AMS in the elderly had a positive rate of $24 \%(10 / 42)$ for febrile and $18 \%(15 / 84)$ for afebrile patients. ${ }^{15}$

Other investigations like blood counts, lactate level, urine analysis, arterial blood gas measurements are important in helping in diagnosis of patients where history and clinical examination has limitations. In a similar but retrospective study done by Kanich et $\mathrm{al}^{\mathbf{1}}$ the importance of history and examination was again demonstrated and the specific features of the clinical evaluation of greatest diagnostic value (with their diagnostic value) included history of present event $(51 \%)$, past medical history $(43 \%)$, and physical examination (41\%). The authors also appreciated the value of response to medical therapies in $39 \%$ of their patients. In the study by Xiao $\mathrm{H}$ Y et al medical history, physical examination, past history, and treatment responses of patients were found important in assessing the causes of AMS. ${ }^{9}$ Their data indicated that the use of these four basic tools could provide $60 \%$ of emergency AMS patients with a clear diagnosis of its cause. ${ }^{9}$ Since we had not included response to treatment in our study to form provisional diagnosis; hence we cannot compare this part with these two studies. Furthermore higher diagnostic accuracy in our study is again in part because of higher number of stroke patients in this cohort; in which diagnosis is usually straight forward for an emergency physician.

\section{Conclusion}

Majority of our patients got a fairly accurate diagnosis for the etiology of AMS in the emergency department. History of present event, past history of similar events, examination are of highest diagnostic value in emergency department in assessing a patient of AMS.CT head is very important in neurological cause of AMS. Random 
blood sugar is very important and of high diagnostic value in patients of AMS.

\section{Bibliography}

1. Kanich W, Brady WJ, Huff JS, et al. Altered mental status: evaluation and etiology in the ED. Am J Emerg Med 2002;20:613e17.

2. Wilber ST. Altered mental status in older emergency department patients. Emerg Med Clin North Am 2006;24:299e316.

3. Hustey FM, Meldon SW, Smith MD, et al. The effect of mental status screening on the care of elderly emergency department patients. Ann Emerg Med 2003;41:678e84.

4. Sporer KA, Solares M, Durant EJ, Wang W, Wu AH, Rodriguez RM. Accuracy of the initial diagnosis among patients with an acutely altered mental status. Emerg Med J. 2013 Mar;30(3):243-6.

5. Han JH, Zimmerman EE, Cutler N, Schnelle J, Morandi A, Dittus RS, et al. Delerium in older emergency department patients: recognition, risk factors, and psychomotor subtypes. Acad Emerg Med 2009; 16: 193-200.

6. Mackay J, Mensah G. The atlas of heart disease and stroke. Geneva: The World Health Organization; 2004.

7. Parvaiz A Shah, G Hussain Bardi, Bashir A Naiku ,A Khaliq Dar, Rakesh K Kaul . Clinicoradiological profile of strokes in Kashmir valley, North-West India: A study from a university hospital .Neurology Asia 2012; 17(1) : 5 - 11

8. Ojaghihaghighi S, Vahdati SS, Mikaeilpour A, Ramouz A. Comparison of neurological clinical manifestation in patients with hemorrhagic and ischemic stroke. World J Emerg Med. 2017;8(1):3438.

9. Xiao HY, Wang YX, Xu TD, et al. Evaluation and treatment of altered mental status patients in the emergency department: Life in the fast lane. World $\mathbf{J}$ Emerg Med. 2012;3(4):270-7.

10. Leong LB, Wei Jian KH, Vasu A, Seow E. Identifying risk factors for an abnormal computed tomographic scan of the head among patients with altered mental status in the Emergency Department. Eur J Emerg Med 2010; 17: 219-223.

11. Haydel MJ, Preston CA, Mills TJ, Luber S, Blaudeau E, DeBlieux PM. Indications for computed tomography in patients with minor head injury. $\mathrm{N}$ Engl $\mathrm{J}$ Med 2000;343:100-5.

12. Stiell IG, Clement CM, Rowe BH, et al. Comparison of the Canadian CT Head Rule and the New Orleans Criteria in patients with minor head injury. JAMA 2005;294:1511-8.

13. Hardy JE, Brennan N. Computerized tomography of the brain for elderly patients presenting to the emergency department with acute confusion. Emerg Med Australas 2008;20:420-4.

14. Shin S, Lee HJ, Shin J, Lee S. Predictors of abnormal brain computed tomography findings in patients with acute altered mental status in the emergency department. Clin Exp Emerg Med 2018;5(1):1-6.

15. Shah K, Richard K, Edlow JA. Utility of lumbar puncture in the afebrile vs. febrile elderly patient with altered mental status: a pilot study. J Emerg Med 2007; 32: 15-18. 